\title{
Evaluation of the $\beta$-Tricalcium phosphate coatings on AISI 316 stainless steel in ringer's solution for 96 hours
}

\begin{abstract}
Ceramic coatings of $\beta$ tricalcium phosphate ( $\beta$-TCP, $\mathrm{Ca} 3(\mathrm{PO} 4) 2)$ deposited by means of magnetron sputtering technique on AISI $316 \mathrm{~L}$ stainless steel substrates were evaluated in terms of its corrosion behavior through electrochemical impedance spectroscopy after being immersed in Ringers' solution for 96hours. Structural molecular characterization of the coatings was carried out by X-ray diffraction (XRD) and Fourier transformed spectroscopy (FTIR). Coatings surface Properties were evaluated by scanning electron microscopy (SEM) and atomic force microscopy (AFM) during the different times of the essay. The immersion essay showed that the like single layer coating of $\beta$-TCP can mitigate corrosion of the steel since. Therefore, is possible to observe a change of $56.37 \%$ in corrosion rate values of AISI 316L stainless steel substrate comparing with corrosion rate of substrate coated with $\beta$-TCP coating under 96hours, but when is compared the $\beta$-TCP coating under 12 hours with the $\beta$-TCP coating under 96 hours of exposure time can be possible obtain an increasing of $56.7 \%$ in corrosion rate values.
\end{abstract}

Keywords: $\beta$-tricalcium phosphate, sputtering, corrosion, cell adhesion, scanning electron microscopy
Volume 2 Issue 2 - 2018

\author{
Aperador W,' Ruíz E,' Orozco-Hernández \\ $\mathrm{G},{ }^{2}$ Caicedo JC, ${ }^{3}$ Amaya $\mathrm{C}^{4}$ \\ 'School of Engineering, Universidad Militar Nueva Granada, \\ Colombia \\ 2Universidad ECCl, Colombia \\ ${ }^{3}$ Tribology, Powder Metallurgy and Processing of Solid Recycling \\ Research Group, Universidad del Valle, Colombia \\ ${ }^{4}$ Development of Materials and Products Research Group, \\ Colombia
}

\begin{abstract}
Correspondence: Caicedo JC, Tribology, Powder Metallurgy and Processing of Solid Recycling Research Group, Universidad
\end{abstract} delValle, Cali, Colombia, Email jcaicedoangulol@gmail.com

Received: April 15, 2018| Published: April 23, 2018
Abbreviations: XRD, X-ray diffraction; SEM, scanning electron microscopy; AFM, atomic force microscopy; FTIR, fourier transformed spectroscopy

\section{Introduction}

The bone tissue is a biomechanical structure formed by specialized cells that are surrounding by a mineralized matrix that is responsible for generating the necessary anchorage for cellular regeneration. This structure is basically formed by a mineral component $(65 \%)$, an organic matrix $(33 \%)$ and a cellular component $(2 \%)$. Mineral or inorganic portion is composed by calcium salts with these concentrations 85 $90 \%$ calcium phosphate, $8-10 \%$ calcium carbonate, $0.3 \%$ calcium fluoride; the combination of those concentrations provides the bone with resistance to the load and the compressive forces. ${ }^{1}$ As for the cellular component are osteoblasts or bone-forming cells that are responsible for performing the bone formation and reabsorption process to maintain the active principles of regeneration. ${ }^{2,3}$ Regeneration processes take place in sectors where damage or loss is present due to physiological or pathological factors. In several cases, regenerative capacities of the cellular system may be insufficient which causes that spontaneous bone healing is not performing properly. It is in these situations where it is necessary to use external materials that contribute to the bone mechanical and biochemical supports to be able to grow. Bone mechanisms are deficient in the loss of large surfaces, bone infections, bad joints, vascular necrosis, osteoporosis, arthrodesis reinforcement, among others. ${ }^{3,4}$

It is in these mechanisms when the use of biomaterials helps the recovery of tissue function and facilitates cell growth. Bioactive materials of a ceramic nature such as calcium phosphate have been used for tissue recovery, the surface properties of these materials help the reproduction and adhesion of osteoblast cells and stimulate the generation and production of collagen and non-collagen proteins to give rise to the regenerated bone matrix. ${ }^{5-7}$ Tricalcium phosphate (TCP) is known as an important phosphate in the use of biomaterials because simulates greatly the bone structure. It is found in two different polymorphic forms: $\alpha, \beta$. The most used until now is the $\beta$-tricalcium phosphate ( $\beta$-TCP) which reveals a good biocompatibility process due to the characteristics of bio-absorption and biomimetism. This means that can reproduce composition, structure, morphology and crystallinity of the natural bone crystals, however, like a ceramic material has low mechanical resistance that limits the charge capacity. ${ }^{8-10}$ Stainless Steel AISI 316LVM has been used as a osteoarticular biomaterial mainly in the fabrication of intramedullary nails, screws, osteosynthesis plates among others. This material has high corrosion resistance and interesting mechanical properties; however, it has disadvantages like the encapsulation of proteins through a fibrous tissue and avoid the direct joint between adjacent bone tissue and metallic surface as well as generate a chronic inflammatory response, fibrosis and the formation of an interface between proteins and adjacent tissue, and in some cases, allergic reactions by nickel and chromium ion liberation. ${ }^{11-13}$

Aiming the yield enhancement of the metallic materials in implants and biological, mechanical, anticorrosive and wear properties and that allow to control bone cells adhesion to the material, some techniques has been generated with the objective of surface chemical and topographic properties modification of the biomaterials. Among surface treatments, coatings deposition allows to generate different surface compositions without altering its intrinsic mechanical properties and enhancing its wear and corrosion resistance. Physical vapor deposition (PVD) technique permit to deposit ceramic materials layers on the surface of metallic materials with the purpose of reduce the ion liberation and to enhance adhesion, proliferation of osteoblastic cells, and augment the phosphate-alkaline activity (bone 
formation enzyme).$^{14}$ As for the modification in the topography of the material PVD process allow to favor the anchorage to the bone tissue and thus reduce the times of osseointegration and to generate a greater transmission of loads between bone and the implant. Efforts to improve such osseointegration have been addressed by creating rough surfaces that increase the surface area available for attachment of the bone to the implant (mechanical locking) and optimize its fixation and stability. ${ }^{15}$ According to the above mentioned mechanical, electrochemical and biological properties of $\beta$-TCP coatings on AISI 316LVM stainless steel substrates surface to enhance the material properties and stablish the principles of bioactivity in osteoblastic cells and the generation of osteoblastic enzymes which activate the regenerative properties and the restructuring of bone tissues.

\section{Experimental procedure}

\section{$\beta$-tricalcium phosphate preparation}

In this work, $\beta$-TCP coatings were deposited onto silicon (100) and AISI 4140 steel substrates by using a multitarget r.f. magnetron sputtering system, with an r.f. source $(13.56 \mathrm{MHz})$ to applying a negative voltage bias on the substrate. The $\beta$-TCP coatings were synthetized from a stoichiometric target with $99.9 \%$ purity and diameter of $4 \mathrm{in}$. Magnetron power of $350 \mathrm{~W}$ was applied to the $\beta$-TCP target. The deposition chamber was initially pumped down to less than $5^{*} 10^{-6} \mathrm{mbar}$ by using a turbomolecular pump, and the (100\%) for Ar gas was introduced into the chamber. An r.f. negative bias voltage of-30 V was used; the substrate temperature was around $250^{\circ} \mathrm{C}$ and the substrate-to-target distance was $7 \mathrm{~cm}$ for all coatings. During the growth process, the chamber pressure was maintained at $2 * 10^{-3} \mathrm{mbar}$. Before deposition, the target and substrates were sputter-cleaned during a $20 \mathrm{~min}$ period.

\section{Coatings characterization}

Thin Films was characterized in its microestructure by SEM with a JEOL NeoScope JCM-5000 microscope. The topography of the films was studied by atomic force microscopy (AFM, Nanosurf Atomic Force Microscope) on an area of $50 \times 50 \mu \mathrm{m}$. For the analysis of the structural composition of the mixtures by infrared spectroscopy, a Nicolet iS10 (Thermo Fisher Scientific) spectrometer operated in Fourier transform mode was used, fitted with a horizontal attenuated total reflectance (HATR) and ZnSe crystal accessory. The spectra were obtained with a resolution of $4 \mathrm{~cm}^{-1}$, in a spectral range of 4000 $650 \mathrm{~cm}^{-1}$ and 32 sweeps. The spectra were processed with the omnic 9.1 software. X-ray diffraction (XRD) analysis was conducted for structural investigations of the films using an X-ray X'pert Pro brand PANalytical with the following characteristics was used: copper anode tube wavelength $=1.54060 \AA$; a goniometer standard resolution containing the geometry $(\theta-2 \theta)$ for performing measurements, symmetrical and asymmetrical and thin-film configurations minimum step size of $0.002^{\circ}$, proportional detector X-ray. To analyze the samples using diffraction techniques in Bragg-Brentano mode proper equipment operation parameters were determined as the optimum angle of incidence ranging from $10^{\circ}$ to $30^{\circ}$ and the counting time of 1 second per step and the step size 0.03 . For optimal angle of incidence diffractograms were made so thin film with a power of $45 \mathrm{kV}$ and $40 \mathrm{~mA}$. The database used ICCD for the identification and quantification of phases through X'Pert High Score software.

\section{Electrochemical test}

Electrochemical tests of the coatings were made by means of a potentiostat-galvanostat Gamry Reference 3000 using electrochemical impedance spectroscopy (EIS) technique with AC voltage of $5 \mathrm{mV}$, frequency range from $100 \mathrm{kHz}$ to $0.001 \mathrm{~Hz}$. First EIS measurement denominated 0 hours was evaluated after 24 hours of immersion, allowing the stabilization of open circuit potential. The electrolyte used during the 96 hours of test to simulate human body fluid conditions was the Ringer's solution. Chemical composition of the solution is $9 \mathrm{~g} / 1$ of $\mathrm{NaCl}, 0.24 \mathrm{~g} / 1$ of $\mathrm{CaCl}_{2}, 0.43 \mathrm{~g} / 1$ of KCl and $0.2 \mathrm{~g} / 1$ of $\mathrm{NaHCO}_{3}$ with $\mathrm{pH}$ value of 7.2 . Temperature of the test was $37^{\circ} \mathrm{C} \pm 1^{\circ} \mathrm{C}$, as this is the normal temperature of human body. In order to maintain this condition of temperature a heating mantle was used accoupled to a electrochemical cell with three electrodes, one of silver-silver chloride $(\mathrm{Ag} / \mathrm{AgCl})$ acting as reference electrode, other of platinum acting as counter electrode and finally the $\beta$-TCP coatings as working electrode as can be seen in Figure 1.

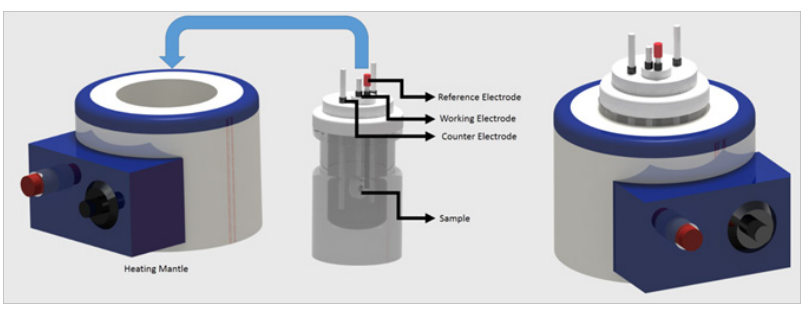

Figure I Electrochemical cell uncoupled before EIS test (left) and electrochemical cell coupled for the EIS test (right).

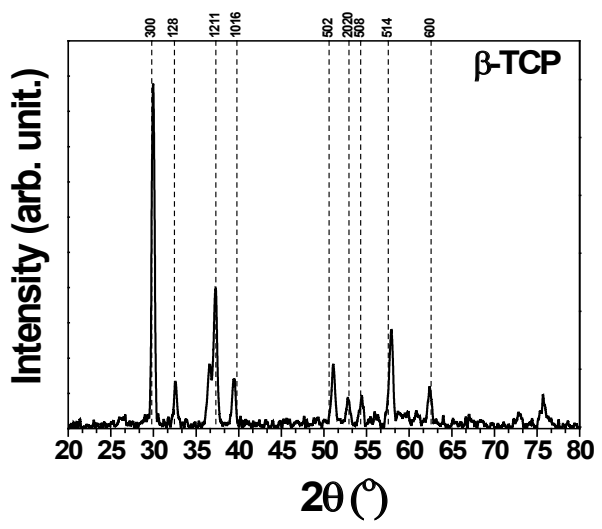

Figure 2 XRD patterns of $\beta$-TCP coatings showing the rhombohedral crystal structure.

\section{Results and discussion}

\section{XRD analysis}

To study of crystalline structure of the prepared $\beta$-TCP coatings, XRD technique was used to obtain the diffraction patterns of each coating. Figure 2 shows the diffraction patterns of $b-\beta$-TCP peaks at low angles, preferential orientations (300), (1112) and (514) for $2 \theta=\left(29.75^{\circ}, 37.16^{\circ}\right.$ and $\left.57.89^{\circ}\right)$, respectively. The results indicate that the preferential orientations, corresponding to the ceramic phase of the coating layers, are in agreement with the Joint Committee on Powder Diffraction Standards (JCPDS) file number 00-009-0169 
from the International Centre for Diffraction Data (ICDD). Figure 2 also exhibits the changes in rhombohedral configurations of $\beta$-TCP as a function of compression stress was also identified due to the changes in the peak morphology when the coating was deposited on silicon surface.

\section{Analysis by FTIR spectroscopy}

The changes in transmittance percentage for each $\beta$-TCP is presented in Figure 3 which shows waves number for each characteristic bond of $\beta$-TCP material in the frequency range 350 $2000 \mathrm{~cm}^{-1}$. After the deconvolution process the spectrum of $\beta$-TCP show congruence in values of wave numbers; According with other authors. ${ }^{16,17}$ In the $\beta$-TCP result is be possible to find vibration bands associated to ceramic materials, in this sense it could be a constructive interference. Vibration bands associated to $\beta$-TCP are described bellow; $\mathrm{CaO}_{3}$ blending vibration band between $900 \mathrm{~cm}^{-1}$ and $1100 \mathrm{~cm}^{-1}$ was found; at $560 \mathrm{~cm}^{-1}$ was observed a vibration band corresponding to tetrahedral structure of $\mathrm{PO}_{4}$, the wave number $920 \mathrm{~cm}^{-1}$ showed a vibration band corresponding to $\mathrm{HPO}_{4}$, the $\mathrm{C}-\mathrm{O}-\mathrm{H}$ bending vibration bands can be observed in $604 \mathrm{~cm}^{-1}$ and finally at $462 \mathrm{~cm}^{-1}$ there is a blending vibration band which is associated to $\mathrm{PO}_{2}$.

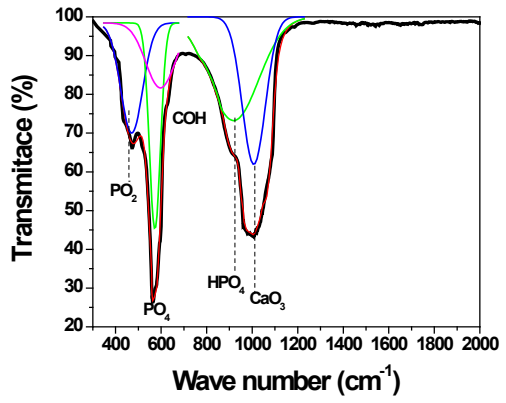

Figure 3 FTIR spectra for $\beta$-TCP coating.

\section{Surface analysis via SEM}

$\beta$-TCP coatings on AISI 316LVM stainless steel before and after corrosion tests were analyzed by SEM technique in an area of $470 \times 390 \mu \mathrm{m}$. Figure $4 \mathrm{a}$ shows the micrograph of the coating before EIS test, it is clearly seen a homogeneous surface represented by the gray color in the figure, this is characteristic of a sputtering process, however there is a structure in the center of the image (red encircled) which is an agglomerate of $\beta$-TCP that has an area of $52.87 \mu \mathrm{m}^{2}$, in the image also can be seen some other smaller structures (blue encircled) that have an average area of $454 \mathrm{~nm}^{2}$ and are produced maybe because of the high power used in the films growth process or maybe by recrystallization process. ${ }^{18}$ Figure $4 \mathrm{~b}$ shows the interface between coated surface and the coated surface where the EIS test was done. The EIS test was made to check the behavior against corrosion processes along time, we evaluated up to 96 hours and the SEM micrographs were taken in the sample zone where the test was done after that time. There are several structures inside the EIS test zone in Figure 3 (red encircled) with an average area of $36.63 \mu \mathrm{m}^{2}$ that could be attributed to $\beta$-TCP dissolved from the surface during the test. In Figure 4c EIS test zone is showed, a homogeneous surface can be seen with some structures (red encircled) with an average area of $25.67 \mu \mathrm{m}^{2}$ again of $\beta$-TCP dissolved during EIS test. The number $\beta$-TCP dissolved particles are higher near the interface or the edge of the EIS test zone and decreases away from this zone.
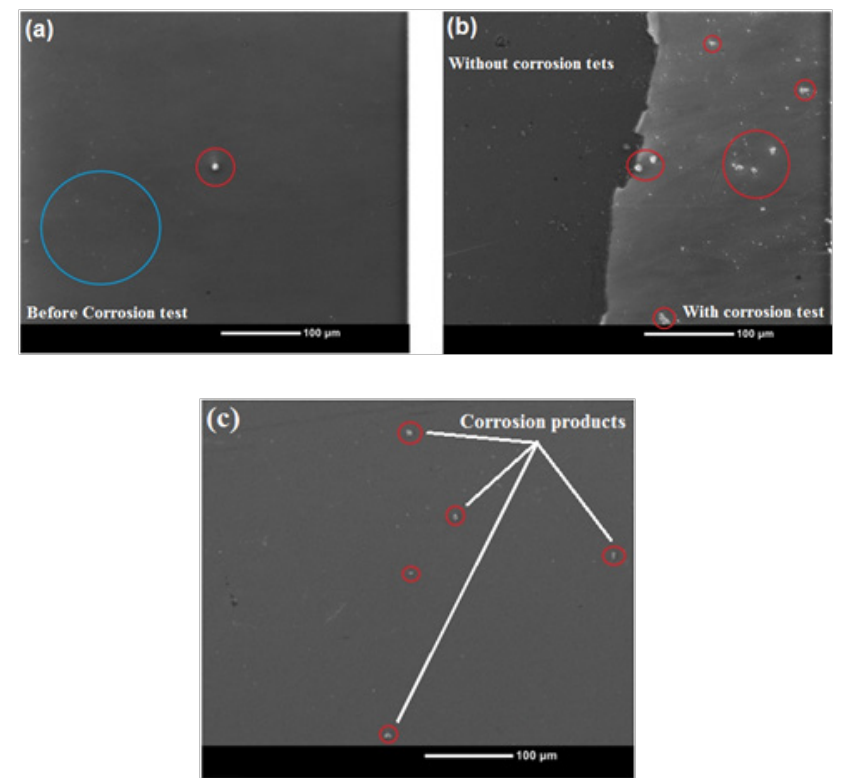

Figure 4 SEM micrograph of $\beta$-TCP coating deposited on surface on AISI 316L stainless steel substrate: (A) before corrosives processes (EIS test), (B) interface between coating outside EIS test zone and inside EIS test zone, and (C) corrosives processes with corrosion products.

\section{Morphological analysis via AFM}

To analyze surface roughness and morphology of the films 3D AFM images were taken on smaller areas compared with SEM technique images. Figure 5 shows an AFM image of the $\beta$-TCP coating surface presenting high homogeneity and small average roughness value of $20.9 \mathrm{~nm}$, these results confirm the above findings obtained by SEM technique. In Figure $5 \mathrm{~b}$ can be seen the interface region between the coating zone that was not subjet of EIS test and the zone where the test was carried out. These image confirm the results showed by SEM in which several structures are placed near the interface and can be seen also a clear step that confirms that the coating in the EIS test zone was detached from the surface leaving the substrate surface exposed and the structures affecting the film surface. Averagre roughness of this zone is about $406 \mathrm{~nm}$, higher than the roughness out of the interface Figure $5 \mathrm{c}$ shows the zone of the sample where the EIS test was done and the coating was detached because of the corrosion processes that take place there, also can be seen lines all over the surface and can be attributed to the substrate surface preparation process of polishing. This area presented an average roughness of $19.2 \mathrm{~nm}$ that is a small value and comparable with the roughness of the coated surface (20.9nm).
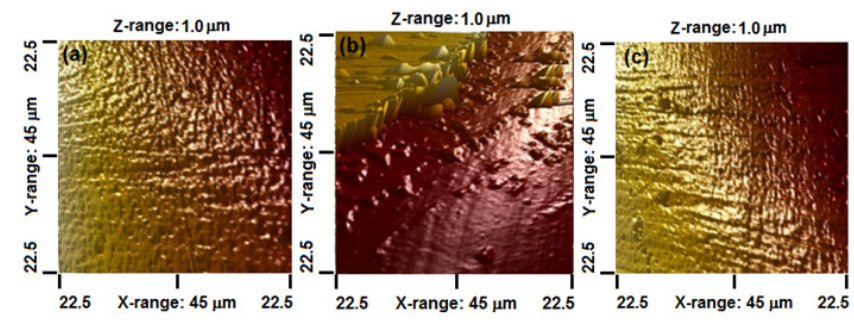

Figure 5 AFM 3D view of $\beta$-TCP coatings surface deposited on steel substrates: (A) before corrosive processes (EIS test), (B) surface image in the interface between corrosive zone and steel surface coated and $(C)$ corrosives processes in all surface with corrosion products 


\section{Electrochemical analysis via nyquist diagram}

From Nyquist diagram can be seen that electrolyte resistance is quite similar in all the essays, this demonstrate that the opposition to the ions mobility of the Ringer's solution is the same through the coating and is not affected or related with evaluation time. In the same diagram, it is observed that the electric response of the coatings layers generates two types of electrical phenomena, one at higher frequencies $(100 \mathrm{kHz}$ to $100 \mathrm{~Hz})$ and other at low frequencies $(1 \mathrm{~Hz}$ to $0.001 \mathrm{~Hz}$ ). Figure 6 shows a well-defined semicircle at elevated frequencies and some diagonal shapes with different slope value at lower frequencies. Figure 6 shows the results in a Nyquist diagram where the corrosion process of the $\beta$-TCP coating immersed in Ringer's solution as electrolyte at a constant temperature of $37^{\circ} \mathrm{C}$ can be analyzed. EIS measurements were made at corrosion potential (Ecorr) and the electrolytic cell was immersed in a thermostated bath, the first one denominated as 0 hours was made after 24 hours of immersion. Then, these measurements were obtained after 12 hours of immersion and measurements after 24, 48, 72 and 96hours were made. In the Nyquist diagrams generated for the evaluated systems up to 96hours of the corrosive solution it is generally observed that total impedance decreases. This is due to the increase in roughness, whose magnitude depends on the size, shape and kinetic energy of the particles reaching surface. As seen by AFM images, surfaces suffered a in vitro structural change against corrosion and a dissolution of the coatings happened, this dissolution is generated during the first hours of the essay since it is observed that in the 24hours of evaluation the total impedance is like that obtained at the beginning, later it decreases in a smaller proportion and stabilizes after 48 hours. So, it can be indicated that this coating confers an excellent corrosion resistance in the medium used for its evaluation, part of the reason for the good biocompatibility of the $\beta$-TCP is due to that corrosion resistance.

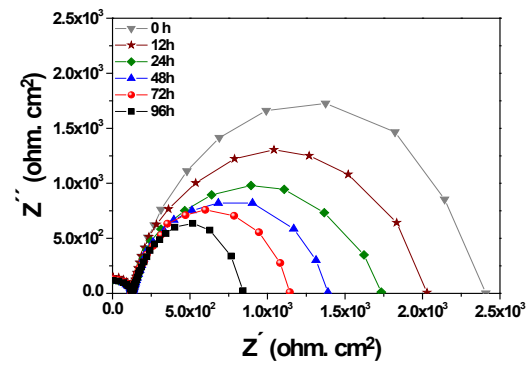

Figure 6 EIS test data for $\beta$-TCP coatings immersed in Ringer's solution during 96 hours of test time at $37^{\circ} \mathrm{C}$.

After 48 hours of evaluation this corrosion resistance generated a spontaneous formation on the surface which consist of a thin layer of oxide, this layer is removed and can be seen with the topographic change evidenced by SEM and AFM results. This is a minimum dissolution due to its physicochemical properties particularly solubility and ionic conductivity, these are determinants in the corrosion velocity and the ions liberation. The quantity of liberated ions depends greatly on the nature and resistance of the ioniccovalent bond, this is the reason because the material dissolves after 24 hours of evaluation and the coating microstructure is modified by the dissolution. Thus, these superficial modifications are due to the interexchange reactions of aqueous ions, generate a partial alteration which after certain time can be less soluble and more stable (48hours). This alteration generate also a change in the surface roughness of the material, however, this does not compromise the in vitro behavior of the corrosion since the wear mechanism was stablished after 72 hours. In Figure 7, the equivalent circuit used to simulate the obtained results by EIS test with different evaluation times is shown. In Table 1 the results are summarized where Rsoln is the electrolyte resistance, Rpo and $C c$ correspond to the reaction of the coating with the solution where it was immersed (Table 2). These elements correspond to the high frequencies response $(100 \mathrm{kHz}$ to $100 \mathrm{~Hz})$, in the table can be seen two behaviors the former up to 24 hours of evaluation where Rpo and $C c$ keep a constant value and after 96hours a decrease in resistance and an increase of the capacitance are shown due to the absorption of some species. The other elements are Ccor that is the electrochemical double layer capacitance and Rcor that is the charge transfer resistance, both are obtained at low frequencies regime $(1 \mathrm{HZ}$ to $0.001 \mathrm{~Hz})$ where it is possible to evaluate substrate-coating interface. Rsoln value can be obtained from the cut-off point of the first semicircle with the axis of absences, this has an average value of $33 \Omega \mathrm{cm}^{2}$. Rcor value can be obtained from the extrapolation of the second semicircle diameter is associated with coating corrosion velocity.

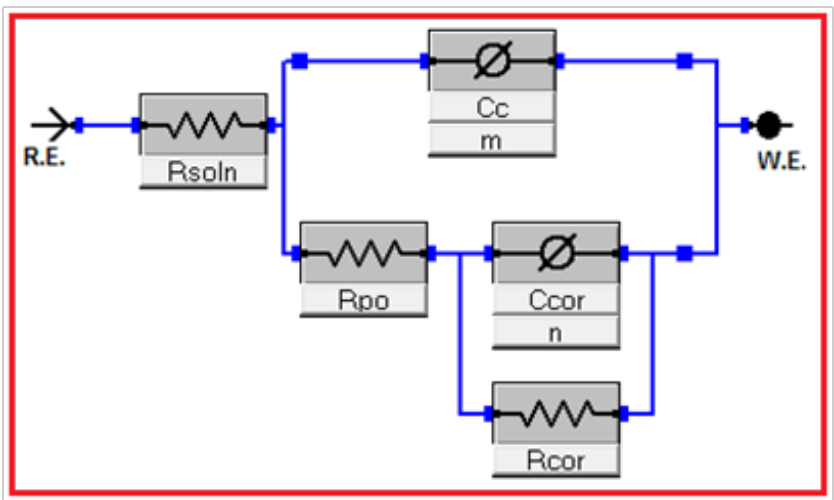

Figure 7 Equivalent electrical circuit used to simulate EIS test data from Figure 6. This is similar to the Randles circuit but includes additionaly a second circuit in series with coating resistance (Rpo) and has one constant phase element (Ccor) in parallel with one resistance (Rcor).

Corrosion rate (corrosion velocity) can be calculated according to Stern and Geary equation that assumes as an approximation that the charge transfer resistance parameter is inversely proportional to corrosion density (icorr) as follows equation (1):

$$
i_{\text {corr }}=\left(\frac{d i}{d E}\right)_{E \rightarrow 0} \frac{\beta_{a} \beta_{c}}{2.303\left(\beta_{a}+\beta_{c}\right)}=\frac{B}{R_{p}}
$$

where $B$ is a constant value that we took as $29 \mathrm{mV}$ assuming that the material corrodes uniformly along the entire surface (generalized corrosion), through Faraday's law the mass loss by corrosion is calculated in micrometers per year (mpy). From that and viewing Figure 6, it was obtained that at low frequencies is where corrosion process is generated and as a consequence of immersion time corrosion velocity increases up to a maximum at 48 hours as well as essay time increases. At higher immersion times corrosion velocity decreases 
showing a stabilization process close to 96 hours. From potential of corrosion values, it was possible demonstrate that increase of exposure times reduce the electrochemical behavior, in this sense the Figure 8 shows an increasing in the corrosion rate while increase the exposure time, however is possible to observe a change of $56.37 \%$ in corrosion rate values of AISI 316L stainless steel substrate comparing with corrosion rate of substrate coated with $\beta$-TCP coating under 96hours, but when is compared the $\beta$-TCP coating under 12 hours with the $\beta$-TCP coating under 96 hours of exposure time can be possible obtain an increasing of $56.7 \%$ in corrosion rate values. This phenomenon can be explained due to that the exposure time increase the possibility that corrosive ions will degrade the coating surface allowing ion migration to the substrate surface.

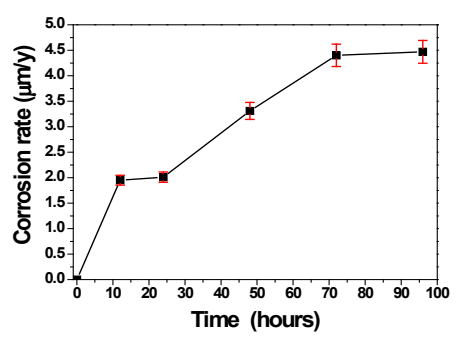

Figure 8 Corrosion rate as function of exposure time for $\beta$-TCP coatings exposed to Ringers solution from 0 hours to 96 hours.

Table I Simulation parameter used for EIS diagrams of $\beta$-TCP coatings exposed to Ringers solution during 96hours

\begin{tabular}{|c|c|c|c|c|c|c|c|}
\hline & $\begin{array}{l}\text { Rsol, } \\
\left(\Omega * \mathrm{~cm}^{2}\right)\end{array}$ & $\begin{array}{l}\text { Rpo, } \\
\left(\Omega * \mathbf{c m}^{2}\right)\end{array}$ & $\begin{array}{l}\text { Rcor, } \\
\mathbf{x} 10^{3} \\
\left(\Omega * \mathrm{~cm}^{2}\right)\end{array}$ & $\begin{array}{l}\text { Cc, } \\
\times 10^{-9} \\
\text { F/ }\end{array}$ & n & $\begin{array}{l}\text { Ccorr, } \\
\times 10^{-6} \\
\text { F } /\end{array}$ & $\mathbf{m}$ \\
\hline $\mathbf{O h}$ & 32.5 & 142.5 & 47.52 & $\frac{\mathbf{c m}^{2}}{24.68}$ & 0.92 & $\frac{\mathbf{c m}^{2}}{60.45}$ & 0.93 \\
\hline $12 \mathrm{~h}$ & 33.1 & 146.4 & 47.09 & 24.84 & 0.96 & 59.23 & 0.91 \\
\hline $24 \mathrm{~h}$ & 34.2 & 130.1 & 46.18 & 24.84 & 0.94 & 62.67 & 0.90 \\
\hline $48 h$ & 32.5 & 122.3 & 20.75 & 26.27 & 0.96 & 84.11 & 0.87 \\
\hline $72 \mathrm{~h}$ & 33.1 & 118.0 & 21.08 & 27.19 & 0.95 & 87.72 & 0.86 \\
\hline $96 \mathrm{~h}$ & 34.0 & 118.4 & 27.98 & 27.91 & 0.93 & 82.95 & 0.87 \\
\hline
\end{tabular}

Table 2 Current density in the corrosion processes (J), mass loss (WL) and corrosion rate $(\mathrm{CR})$ from Faraday's law, obtained for each of the evaluation times

\begin{tabular}{llll}
\hline Time (hours) & $\mathbf{W}_{\mathbf{L}}\left(\mathbf{g} / \mathbf{c m}^{2}\right)$ & $\mathbf{C R}(\boldsymbol{\mu m} / \mathbf{y})$ & $\mathbf{J}\left(\boldsymbol{\mu A} / \mathbf{c m}^{2}\right)$ \\
\hline $\mathbf{0}$ & 0 & 0 & 0 \\
$\mathbf{1 2}$ & $2.11 \times 10^{-3}$ & 1.95 & 0.61 \\
$\mathbf{2 4}$ & $4.35 \times 10^{-3}$ & 2.01 & 0.624 \\
$\mathbf{4 8}$ & 0.0286 & 3.31 & 1.03 \\
$\mathbf{7 2}$ & 0.0285 & 4.40 & 1.37 \\
$\mathbf{9 6}$ & 0.0193 & 4.47 & 1.39 \\
\hline
\end{tabular}

\section{Conclusion}

XRD and FTIR results indicate the coherent synthesis of $\beta$-Tricalcium phosphate $\beta-\mathrm{Ca}_{3}(\mathrm{PO} 4)_{2}(\beta-\mathrm{TCP})$ or ((Poly-(1-4)-2Amino-2-deoxy- $\beta$-D-Glucan) coating systems in $\beta$-TCP by the preferential orientation (300) in the rhombohedral structure, it was evidenced by the absorbance of vibration bands in FTIR spectra. Electrochemical impedance spectroscopy results show that $\beta$-TCP
$\left(\mathrm{C}_{6} \mathrm{H}_{11} \mathrm{NO}_{4}\right) \mathrm{n}$ coatings improve their electrochemical resentence in relation uncoated steel substrate. Also the corrosion effect increase when the corrosion exposure time under was increased coatings improve their values of corrosion rate while increase the exposition time under Hanks solution showing an increasing of $56.37 \%$.

\section{Acknowledgements}

This work was supported by the Universidad Militar de Nueva Granada and the Universiad del Valle (EIMAT) Cali Colombia.

\section{Conflict of interest}

Authors declare that there is no conflict of interest.

\section{References}

1. Aerssens J, Dequeker J, Mbuyi-Muamba JM. Bone tissue composition: Biochemical anatomy of bone. Clinical Rheumatology.1994;13(1):54-62.

2. Wang X, Nyman JS, Dong X, et al. Fundamental Biomechanics in Bone Tissue Engineering. Synthesis Lectures on Tissue Engineering. 2010;2:225.

3. Petite H, Viateau V, Bensaïd W, et al. Tissue-engineered bone regeneration. Nat Biotechnol. 2000;18(9):959-963.

4. Dimitriou R, Jones E, McGonagle D, et al. Bone regeneration: current concepts and future directions. BMC Med. 2011;9:66.

5. Araújo MVF, Mendes VC, Chattopadhyay P, et al. Low-temperature particulate calcium phosphates for bone regeneration. Clin Oral Implants Res. 2010;21(6):632-641.

6. Vallet-Regí M, González-Calbet JM. Calcium phosphates as substitution of bone tissues. Progress in Solid State Chemistry. 2004;32(1-2):1-31.

7. Wolf-Brandstetter C, Hempel U, Clyens S, et al. The impact of heat treatment on interactions of contact-poled biphasic calcium phosphates with proteins and cells. Acta Biomater. 2012;8(9):3468-3477.

8. Koepp HE, et al. Biocompatibility and osseointegration of beta-TCP: histomorphological and biomechanical studies in a weight-bearing sheep model. J Biomed Mater Res B Appl Biomater. 2004;70(2):209-217.

9. Zhang X, Jiang F, Groth $\mathrm{T}$, et al. Preparation, characterization and mechanical performance of dense beta-TCP ceramics with/without magnesium substitution. J Mater Sci Mater Med. 2008;19(9):3063-3070.

10. Ozkan S, Kalyon DM, Yu X. Functionally graded beta-TCP/PCL nanocomposite scaffolds: in vitro evaluation with human fetal osteoblast cells for bone tissue engineering. J Biomed Mater Res. 2010;92(3):10071018 .

11. Wallinder D, Pan J, Leygraf C, et al. EIS and XPS study of surface modification of 316LVM stainless steel after passivation. Corros Sci. 1998;41(2):275-289.

12. Gristina. Biomaterial-centered infection: microbial adhesion versus tissue integration. Science. 1987;237(4822):1588-1595.

13. Bou-Saleh Z, Shahryari A, Omanovic S, Enhancement of corrosion resistance of abiomedical grade 316LVM stainless steel by potentiodynamic cyclic polarization. Thin Solid Films. 2007;515(11):4727-4737.

14. Chaijaruwanich A. Coating techniques for biomaterials: A review. Chiang Mai University Journal of Natural Sciences. 2011;10(1):39-50.

15. Barfeie, Wilson J, Rees J. Implant surface characteristics and their effect on osseointegration. Br Dent J. 2015;218(5):E9.

16. Martinez R, Estupiñan H, Cordoba E, et al. Scientia et Technica 2007;36:231. 
17. Salma K, Berzina-Cimdina L, Borodajenko N. Calcium phosphate bioceramics prepared from wet chemically precipitated powders. Processing and Application of Ceramics. 2010;4(1):45-51.
18. Vandijk K, Schaeken H, Wolke J, et al. Influence of annealing temperature on RF magnetron sputtered calcium phosphate coatings. Biomaterials. $1996 ; 17(4): 405-410$. 